\title{
Influence of Anions on Intervalence Charge Transfer (IVCT) in Mixed-Valence Dinuclear Complexes $^{\dagger}$
}

\author{
Elizabeth A. Fellows and F. Richard Keene* \\ School of Pharmacy and Molecular Sciences, James Cook University, Townsville, Queensland 4811, Australia
}

Received: November 30, 2006; In Final Form: January 24, 2007

\begin{abstract}
Spectroelectrochemical studies of the intervalence charge transfer (IVCT) characteristics of both diastereoisomeric forms of the dinuclear complex $\left[\left\{\mathrm{Ru}(\mathrm{bpy})_{2}\right\}_{2}\left(\mu-\mathrm{dpi}^{-}\right)\right]^{n+}\left[\mathrm{bpy}=2,2^{\prime}\right.$-bipyridine; $\mathrm{dpi}^{-}=4,5-\mathrm{di}(2-$ pyridyl)imidazolate] showed that the degree of inter-metal electronic coupling (or valence delocalization) is dependent on stereochemical identity. Increasing the relative concentration of the strongly associating anion toluene-4-sulfonate in acetonitrile/[(n- $\left.\left.\mathrm{C}_{4} \mathrm{H}_{9}\right)_{4} \mathrm{~N}\right]\left\{\mathrm{B}\left(\mathrm{C}_{6} \mathrm{~F}_{5}\right)_{4}\right\}$ solution differentially decreased the level of delocalization for the two diastereoisomers. In a comparative investigation of electrochemical and spectroelectrochemical techniques of the anion-induced electron localization in $\left[\left\{\mathrm{Ru}(\mathrm{bpy})_{2}\right\}_{2}(\mu \text {-dpo })\right]^{5+}[\mathrm{dpo}=3,4-$ di(2-pyridyl)-1,2,5-oxadiazole], differences were observed between the two methods in the order and extent of effects induced by a number of inorganic anions $\left(\mathrm{PF}_{6}^{-}, \mathrm{BF}_{4}^{-}, \mathrm{ClO}_{4}^{-}\right)$. It was determined that the measure of coupling derived from electrochemical methods was less reliable than that obtained from spectral methods. Comparative electrochemical studies were undertaken on $\left[\left\{\mathrm{M}(\mathrm{bpy})_{2}\right\}_{2}(\mu-\mathrm{BL})\right]^{n+}\{\mathrm{M}=\mathrm{Ru}, \mathrm{Os} ; \mathrm{BL}=\mathrm{dpo}$, dpi $^{-}$), which revealed substantial differences in $\Delta E_{\text {ox }}$ (the separation between the redox potentials for the $\mathrm{M}^{\mathrm{II}}-\mathrm{M}^{\mathrm{II}} / \mathrm{M}^{\mathrm{III}}-\mathrm{M}^{\mathrm{II}}$ and $\mathrm{M}^{\mathrm{II}}-\mathrm{M}^{\mathrm{III}} / \mathrm{M}^{\mathrm{III}}-\mathrm{M}^{\mathrm{III}}$ couples) for the two metal centers and therefore the comproportionation constant $K_{\mathrm{c}}$, dependent on the neutral or anionic nature of the bridging ligand.
\end{abstract}

\section{Introduction}

Dinuclear ligand-bridged mixed-valence complexes $\left[\left\{\mathrm{L}_{n} \mathrm{M}^{\mathrm{II}}\right\}(\mu-\mathrm{BL})\left\{\mathrm{M}^{\mathrm{III}} \mathrm{L}_{n}\right\}\right]^{n+}(\mathrm{M}=$ metal centers, $\mathrm{L}=$ terminal ligands, and $\mathrm{BL}=$ bridging ligand) have played a pivotal role in the assessment of activation barriers to intramolecular electron transfer since the disclosure in 1973 of the Creutz-Taube ion, $\left[\left\{\mathrm{Ru}\left(\mathrm{NH}_{3}\right)_{5}\right\}\left(\mu \text {-pyz) }\left\{\mathrm{Ru}\left(\mathrm{NH}_{3}\right)_{5}\right\}\right]^{5+}\right.$ (pyz $=$ pyrazine $) .{ }^{1}$ The absorption band observed in the near-infrared (NIR) region of the electronic spectrum for such species is identified as the optically induced intervalence charge transfer (IVCT) transition, which provides a sensitive and powerful insight into electronic coupling of the metal centers through the bridge by an electron superexchange mechanism, because the energy $\left(\nu_{\max }\right)$, intensity $(\epsilon)$, and bandwidth $\left(\Delta v_{1 / 2}\right)$ of these transitions can be quantitatively related to the factors that influence the activation barrier to electron transfer. ${ }^{2,3}$

For valence-localized mixed-valence dinuclear systems, Hush ${ }^{2,3}$ proposed the relationship

$$
v_{\max }=\lambda+\Delta E_{\mathrm{o}}+\Delta E^{\prime}
$$

where $\lambda$ is a reorganizational contribution that is a consequence of Franck-Condon restrictions, $\Delta E_{\mathrm{o}}$ arises from redox asymmetry, and $\Delta E^{\prime}$ represents the energy contributions due to spinorbit coupling and/or ligand field asymmetry. The reorganizational contribution can be further subdivided into inner- and outer-sphere components $\lambda_{\mathrm{i}}$ and $\lambda_{\mathrm{o}}: \lambda_{\mathrm{i}}$ corresponds to the energy required for reorganization of the metal-ligand and intra-ligand bond lengths and angles, and $\lambda_{\mathrm{o}}$ is the energy required for reorganization of the surrounding solvent medium. For a

\footnotetext{
† Part of the special issue "Norman Sutin Festschrift".

* To whom correspondence should be addressed. Fax: +61-(0)7-47816078. E-mail: Richard.Keene@jcu.edu.au.
}

symmetrical di-ruthenium complex of this type, $\lambda_{\mathrm{i}}$ is minimal as the bond lengths and angles in ruthenium polypyridyl complexes undergo only very minor changes on $\mathrm{Ru}^{\mathrm{II} / \mathrm{II}}$ interconversion, ${ }^{4-6} \Delta E_{\mathrm{o}}$ is small for a symmetrical complex, ${ }^{7}$ and spin-orbit coupling is very small for the ruthenium centers. Accordingly, the outer-sphere reorganizational component $\lambda_{\mathrm{o}}-$ associated with solvent and anion reorganization-constitutes the major barrier to electron transfer.

Two recent publications from our laboratory have discussed solvent reorganizational effects on IVCT; ${ }^{8,9}$ the present work addresses the issue of anion effects.

The complexes involved are of the form $\left[\left\{\mathrm{M}(\mathrm{bpy})_{2}\right\}_{2}(\mu-\right.$ $\mathrm{BL})]^{n+}$, where $\mathrm{M}=\mathrm{Ru}$ and $\mathrm{Os}$ and $\mathrm{BL}=3,4-\mathrm{di}(2$-pyridyl)1,2,5-oxadiazole (dpo) or 4,5-di(2-pyridyl)imidazolate (dpi ${ }^{-}$) as shown in Figure 1. The synthesis, stereoisomerism, structural features, spectral and electrochemical characterization, and some IVCT properties of the ruthenium complexes have been published previously. ${ }^{10,11}$ The dpo bridging ligand has very lowlying $\pi^{*}$ orbitals, which result in a very delocalized system with the strong electronic coupling occurring by an electron-transfer mechanism. The dpi ${ }^{-}$-bridged complexes are less delocalized, but the anionic character of $\mathrm{dpi}^{-}$determines that electronic coupling will be described by a hole transfer mechanism. ${ }^{12,13}$

Access to diastereoisomeric forms of the four species provides a particular opportunity for an intricate insight into anion participation in the charge-transfer process. This paper reports electrochemical and spectroelectrochemical studies of the effect of anions on the IVCT processes in the ruthenium and osmium complexes, which allows a telling comparison of electrochemical and spectral techniques in the assessment of valence-localized cations in this series of complexes. 

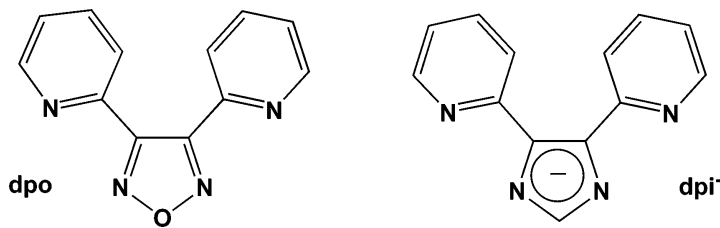

Figure 1. The di-bidentate bridging ligands 3,4-di(2-pyridyl)-1,2,5oxadiazole (dpo) and 4,5-di(2-pyridyl)imidazolate $\left(\mathrm{dpi}^{-}\right)$.

\section{Experimental Section}

Physical Measurements. 1D and 2D ${ }^{1} \mathrm{H}$ NMR spectra were performed using a Varian Mercury $300 \mathrm{MHz}$ spectrometer. The ${ }^{1} \mathrm{H}$ NMR chemical shifts for all complexes are reported relative to $99.9 \% \mathrm{~d}_{3}$-acetonitrile $\left[\mathrm{CD}_{3} \mathrm{CN}\right.$; Cambridge Isotope Laboratories (CIL)] at $\delta=1.93 \mathrm{ppm}$. ${ }^{1} \mathrm{H}$ NMR assignments were performed with the assistance of COSY experiments to identify each pyridine ring system.

Electrochemical measurements were performed using a Bioanalytical Systems (BAS) 100A Electrochemical Analyzer. Cyclic (CV) and square wave (SWV) voltammograms were recorded at room temperature in a standard three-electrode cell using a glassy carbon or platinum button working electrode, a platinum wire auxiliary electrode, and an $\mathrm{Ag} / \mathrm{Ag}^{+}$reference electrode. Ferrocene was added on completion of each experiment as an internal standard, and all potentials are quoted in $\mathrm{mV}$ relative to $\left[\mathrm{Fe}(\mathrm{Cp})_{2}\right]^{+/ 0} .{ }^{14}$ For standard measurements, a 1 $\mathrm{mM}$ solution of the complex in acetonitrile contained $0.1 \mathrm{M}$ $\left[\left(n-\mathrm{C}_{4} \mathrm{H}_{9}\right)_{4} \mathrm{~N}\right] \mathrm{PF}_{6}$ or $0.02 \mathrm{M}\left[\left(n-\mathrm{C}_{4} \mathrm{H}_{9}\right)_{4} \mathrm{~N}\right]\left\{\mathrm{B}\left(\mathrm{C}_{6} \mathrm{~F}_{5}\right)_{4}\right\}$ as electrolyte. In anion dependence studies, the electrolyte was 0.02 $\mathrm{M}\left[\left(n-\mathrm{C}_{4} \mathrm{H}_{9}\right)_{4} \mathrm{~N}\right] \mathrm{X}$, where $\mathrm{X}=\left\{\mathrm{B}\left(\mathrm{C}_{6} \mathrm{~F}_{5}\right)_{4}\right\}^{-}, \mathrm{BF}_{4}{ }^{-}, \mathrm{PF}_{6}{ }^{-}$, or $\mathrm{ClO}_{4}{ }^{-}$. Cyclic voltammetry was performed with a scan rate of $100 \mathrm{mV} \mathrm{s}^{-1}$ and a sensitivity of $1 \mu \mathrm{A} \mathrm{V}^{-1}$; square wave voltammetry was performed with a sensitivity of $1 \mu \mathrm{A} \mathrm{V}^{-1}$, a step potential of $4 \mathrm{mV}$, a square wave amplitude of $25 \mathrm{mV}$, and a square wave frequency of $15 \mathrm{~Hz}$. All SWV potentials are reported to $\pm 3 \mathrm{mV}$. The comproportionation constant $K_{\mathrm{c}}$ was obtained from $\Delta E_{\mathrm{OX}}$ (the separation of the potentials for the $\mathrm{M}^{\mathrm{III}}-\mathrm{M}^{\mathrm{III}} / \mathrm{M}^{\mathrm{III}}-\mathrm{M}^{\mathrm{II}}$ and $\mathrm{M}^{\mathrm{III}}-\mathrm{M}^{\mathrm{II}} / \mathrm{M}^{\mathrm{II}}-\mathrm{M}^{\mathrm{II}}$ oxidations), obtained from the electrochemical measurements according to eq $2 .{ }^{6}$

$$
K_{\mathrm{c}}=\exp \left(\Delta E_{\mathrm{ox}} F / R T\right)
$$

UV/visible/NIR spectroelectrochemistry was performed at room temperature using a CARY 5E UV/vis/NIR spectrophotomer interfaced to Varian WinUV software. The absorption spectra of the electrogenerated mixed-valence species were obtained in situ in an optically semi-transparent thin-layer electrosynthetic (OSTLE) cell (path length $=0.06835 \mathrm{~cm}$ ). The cell consisted of a platinum gauze working electrode in the path of the spectrophotometer (with matching gauze in the reference beam), a platinum wire auxiliary electrode, and a silver wire reference electrode. ${ }^{15,16}$ The cell potential was controlled using a BAS CV27 voltammograph coupled to a digital multimeter to allow both current and voltage to be monitored simultaneously. Measurements for both diastereoisomers of the ruthenium complexes $\left[\left\{\mathrm{Ru}(\mathrm{bpy})_{2}\right\}_{2}\left(\mu-\mathrm{dpi}^{-}\right)\right]^{n+}$ and $\left[\left\{\mathrm{Ru}(\mathrm{bpy})_{2}\right\}_{2}(\mu-\right.$ $\mathrm{dpo})]^{n+}$ were made in acetonitrile solutions containing the electrolytes $0.02 \mathrm{M}\left[\left(n-\mathrm{C}_{4} \mathrm{H}_{9}\right)_{4} \mathrm{~N}\right]\left\{\mathrm{B}\left(\mathrm{C}_{6} \mathrm{~F}_{5}\right)_{4}\right\}, 0.02 \mathrm{M}[(n-$ $\left.\left.\mathrm{C}_{4} \mathrm{H}_{9}\right)_{4} \mathrm{~N}\right]$ (toluene-4-sulfonate) or mixtures of the two (the total $\left[\left(n-\mathrm{C}_{4} \mathrm{H}_{9}\right)_{4} \mathrm{~N}\right]^{+}$concentration always being maintained at 0.02 $\mathrm{M}$ to keep ionic strength consistent), with a complex concentration ca. $0.5 \mathrm{mM}$; diastereoisomers of $\left[\left\{\mathrm{Ru}(\mathrm{bpy})_{2}\right\}_{2}(\mu \text {-dpo })\right]^{n+}$ were also studied in $0.02 \mathrm{M}\left[\left(n-\mathrm{C}_{4} \mathrm{H}_{9}\right)_{4} \mathrm{~N}\right] \mathrm{X}$, where $\mathrm{X}=$ $\left\{\mathrm{B}\left(\mathrm{C}_{6} \mathrm{~F}_{5}\right)_{4}\right\}^{-}, \mathrm{BF}_{4}^{-}, \mathrm{PF}_{6}^{-}$, or $\mathrm{ClO}_{4}^{-}$as well as $0.1 \mathrm{M}[(n-$ $\left.\left.\mathrm{C}_{4} \mathrm{H}_{9}\right)_{4} \mathrm{~N}\right] \mathrm{PF}_{6}$. The absorbance spectra of the electrogenerated species were recorded at regular intervals and checked for reversibility by regeneration of the initial unoxidized complex spectrum after the mixed-valence spectrum had been obtained, and by observation of clean isosbestic points. The IVCT spectra were scaled as $\int \epsilon(v) / v \mathrm{~d} v .^{2,17,18}$ The uncertainties in the energies $\left(v_{\max }\right)$, intensities $\left[(\epsilon / v)_{\max }\right]$, and bandwidths $\left(\Delta v_{1 / 2}\right)$ were estimated as $\pm 10 \mathrm{~cm}^{-1}, \pm 0.001 \mathrm{M}^{-1}$, and $\pm 10 \mathrm{~cm}^{-1}$, respectively.

Elemental microanalyses were performed at the Microanalytical Unit in the Research School of Chemistry, Australian National University.

Materials. 2,2'-Bipyridine (bpy; Aldrich, 99+\%), potassium hexafluorophosphate $\left(\mathrm{KPF}_{6} ;\right.$ Aldrich, $\left.98 \%\right)$, ethylene glycol (Ajax, 95\%), sodium toluene-4-sulfonate (Aldrich, 98\%), Amberlite IRA-400 (Aldrich) anion exchange resin $\left(\mathrm{Cl}^{-}\right.$form), and laboratory reagent solvents were used as received. Tetra- $n$ butylammonium hexafluorophosphate $\left(\left[n-\mathrm{C}_{4} \mathrm{H}_{9}\right)_{4} \mathrm{~N}\right] \mathrm{PF}_{6}$; Fluka, $99+\%)$, tetra- $n$-butylammonium perchlorate $\left\{\left[\left(n-\mathrm{C}_{4} \mathrm{H}_{9}\right)_{4} \mathrm{~N}\right] \mathrm{ClO}_{4}\right.$, Fluka, $>99 \%\}$, and tetra- $n$-butylammonium tetrafluoroborate $\left\{\left[\left(n-\mathrm{C}_{4} \mathrm{H}_{9}\right)_{4} \mathrm{~N}\right] \mathrm{BF}_{4}\right.$, Fluka, $\left.>99 \%\right\}$ were dried in vacuo at 60 ${ }^{\circ} \mathrm{C}$ prior to use, and ferrocene $\left\{\left[\mathrm{Fe}(\mathrm{Cp})_{2}\right] ; \mathrm{BDH}\right\}$ was purified by sublimation prior to use. SP Sephadex C-25 and silica gel (200-400 mesh, $60 \AA$, Aldrich) were employed for the chromatographic separation and purification of ruthenium complexes. Immediately before use, acetonitrile $\left(\mathrm{CH}_{3} \mathrm{CN}\right.$; Aldrich, 99.9+\%) was distilled over $\mathrm{CaH}_{2}$.

The bridging ligands 2,3-bis(2-pyridyl)quinoxaline (dpb), ${ }^{19}$ 3,4-di(2-pyridyl)-1,2,5-oxadiazole (dpo), ${ }^{10}$ and 4,5-di(2-pyridyl)imidazole $(\mathrm{dpiH})^{11}$ were prepared by literature methods [the latter two were a gift from Professor Peter Steel (University of Canterbury, Christchurch, New Zealand)]. The ruthenium complexes $\left[\left\{\mathrm{Ru}(\mathrm{bpy})_{2}\right\}_{2}(\mu\right.$-dpb) $]\left(\mathrm{PF}_{6}\right)_{4}\{\mathrm{dpb}=2,3$-bis(2-pyridyl)quinoxaline $\},{ }^{20}\left[\left\{\mathrm{Ru}(\mathrm{bpy})_{2}\right\}_{2}(\mu\right.$-dpo $\left.)\right]\left(\mathrm{PF}_{6}\right)_{4},{ }^{10}$ and $[\{\mathrm{Ru}-$ $\left.\left.(\mathrm{bpy})_{2}\right\}_{2}\left(\mu-\mathrm{dpi}^{-}\right)\right]\left(\mathrm{PF}_{6}\right)_{3}{ }^{11}$ were synthesized and chromatographically separated into their diastereoisomeric forms, as reported previously. The electrolyte $\left[\left(n-\mathrm{C}_{4} \mathrm{H}_{9}\right)_{4} \mathrm{~N}\right]\left\{\mathrm{B}\left(\mathrm{C}_{6} \mathrm{~F}_{5}\right)\right\}^{8,21}$ and the osmium precursor $\left[\mathrm{Os}(\mathrm{bpy})_{2} \mathrm{Cl}_{2}\right] \cdot 2 \mathrm{H}_{2} \mathrm{O}^{22,23}$ were obtained using literature methods. The electrolyte $\mathrm{Cs}\left(\mathrm{CB}_{11} \mathrm{H}_{6} \mathrm{Br}_{6}\right)^{24}$ was provided by Dr. Richard Webster (Australian National University).

Complex Syntheses and Diastereoisomer Separation. [ $\{\mathrm{Os}$ $\left.\left.(\text { bpy })_{2}\right\}_{2}\left(\mu-d p i^{-}\right)\right]\left(P_{6}\right)_{3}$. [Os(bpy $\left.)_{2} \mathrm{Cl}_{2}\right] \cdot 2 \mathrm{H}_{2} \mathrm{O}(94.3 \mathrm{mg}, 0.155$ $\mathrm{mmol})$ and $\mathrm{dpiH}(16.5 \mathrm{mg}, 0.0747 \mathrm{mmol})$ were dissolved in ethylene glycol $(2 \mathrm{~mL})$ containing saturated aqueous $\mathrm{NaOH}(3$ drops), and the mixture was heated at reflux for $10 \mathrm{~min}$ in a modified microwave oven (at high power) in 1 min intervals with stirring in between. The hot solution was cooled to room temperature and then diluted with $\mathrm{H}_{2} \mathrm{O}(50 \mathrm{~mL})$. Separation of the dinuclear complex from the crude reaction mixture was achieved by gradient elution chromatography (column dimensions $\sim 25 \mathrm{~cm} \times \sim 3 \mathrm{~cm}$ diameter) with a SP Sephadex C-25 cation exchanger as support. The complex was loaded as the reaction mixture: the mononuclear products eluted with $0.2 \mathrm{M}$ $\mathrm{NaCl}$ and the dinuclear species with a $0.4 \mathrm{M} \mathrm{NaCl}$ solution. The dinuclear complex was isolated by addition of solid $\mathrm{KPF}_{6}$ to the eluate and extraction with dichloromethane. The organic layer was evaporated to dryness on a rotary evaporator after drying with anhydrous $\mathrm{Na}_{2} \mathrm{SO}_{4}$ : yield, $32 \mathrm{mg}(27 \%)$.

Diastereoisomeric separation was achieved using a SP Sephadex C-25 cation exchanger as support in columns that were typically $90 \mathrm{~cm}$ in length by $1.6 \mathrm{~cm}$ in diameter. The crude complex was converted from the $\mathrm{PF}_{6}{ }^{-}$to the $\mathrm{Cl}^{-}$salt in aqueous solution using an Amberlite anion-exchange resin. The solution was filtered, and the filtrate was loaded onto a column and eluted with $0.2 \mathrm{M}$ sodium toluene-4-sulfonate solution; ${ }^{25,26}$ diastere- 
oisomeric separation was achieved within one pass down the chromatographic column with the rac isomer being eluted first followed by the meso (both forms were brown). Each isomer was precipitated by addition of $\mathrm{KPF}_{6}$ and isolated by extraction into dichloromethane, and the solvent was removed by rotary evaporation.

Because of the very strong association between the eluent anion and the dinuclear complex, special care was needed to ensure complete removal of the anion from the isolated sample. Purification of each isolated complex was achieved by adsorption onto a short column $(5 \mathrm{~cm}$ in length $\times 1.5 \mathrm{~cm}$ in diameter $)$ of silica gel (200-400 mesh) equilibrated in AR acetone. The complexes were loaded as the $\mathrm{PF}_{6}{ }^{-}$salt dissolved in acetone, washed with copious amounts of acetone, water, and then acetone, and eluted with a saturated solution $(\sim 5 \%)$ of $\mathrm{NH}_{4-}$ $\mathrm{PF}_{6}$ in $\mathrm{AR}$ acetone. An equal volume of water was added, and the acetone was removed under reduced pressure. The complexes were isolated by vacuum filtration through Celite and washed with chilled water. The complexes were subsequently removed from the Celite using $\mathrm{AR}$ acetone, which was evaporated under reduced pressure, and the compound was dried under vacuum.

Meso. Anal. Calcd. for $\mathrm{Os}_{2} \mathrm{C}_{53} \mathrm{~N}_{12} \mathrm{H}_{41} \mathrm{P}_{3} \mathrm{~F}_{18}$ : C, 38.3; H, 2.49; $\mathrm{N} ; 10.1$. Found: $\mathrm{C}, 37.8 ; \mathrm{H}, 2.81 ; \mathrm{N}, 9.7 .{ }^{1} \mathrm{H}$ NMR $(\delta \mathrm{ppm}$, $\left.\mathrm{CD}_{3} \mathrm{CN}\right): 5.34(1 \mathrm{H}, \mathrm{s}), 7.00-7.06(6 \mathrm{H}, \mathrm{m}), 7.19(2 \mathrm{H}, J=7.2$ $\mathrm{Hz}, \mathrm{t}), 7.388(2 \mathrm{H}, J=6.3, \mathrm{t}), 7.434(2 \mathrm{H}, J=6, \mathrm{~d}), 7.49(2 \mathrm{H}$, $J=5.7 \mathrm{~Hz}, \mathrm{~d}), 7.52(2 \mathrm{H}, J=5.7 \mathrm{~Hz}, \mathrm{~d}), 7.63(2 \mathrm{H}, J=98.4$ $\mathrm{Hz}, \mathrm{t}), 7.66(2 \mathrm{H}, J=7.5 \mathrm{~Hz}, \mathrm{t}), 7.733(2 \mathrm{H}, J=6 \mathrm{~Hz}, \mathrm{~d}), 7.770-$ $7.865(6 \mathrm{H}, \mathrm{m}), 8.097(2 \mathrm{H}, J=6 \mathrm{~Hz}, \mathrm{~d}), 8.27(4 \mathrm{H}, J=8.7 \mathrm{~Hz}$, d), $8.40(2 \mathrm{H}, J=8.4 \mathrm{~Hz}, \mathrm{~d}), 8.47(2 \mathrm{H}, J=9.3 \mathrm{~Hz}, \mathrm{~d}), 8.50$ $(2 \mathrm{H}, J=9.3 \mathrm{~Hz}, \mathrm{~d})$. Rac. Anal. Calcd. for $\mathrm{Os}_{2} \mathrm{C}_{53} \mathrm{~N}_{12} \mathrm{H}_{41} \mathrm{P}_{3} \mathrm{~F}_{18}$. $14 \mathrm{H}_{2} \mathrm{O}$ : C, 33.3; H, 3.63; N, 8.8. Found: C, 32.9; H, 2.89; N, 9.1. ${ }^{1} \mathrm{H}$ NMR $\left(\delta \mathrm{ppm}, \mathrm{CD}_{3} \mathrm{CN}\right): 5.71(1 \mathrm{H}, \mathrm{s}), 6.96-7.04(8 \mathrm{H}$, $\mathrm{m}), 7.22(2 \mathrm{H}, J=6.3 \mathrm{~Hz}, \mathrm{t}), 7.38(2 \mathrm{H}, J=6 \mathrm{~Hz}, \mathrm{t}), 7.41(2 \mathrm{H}$, $J=5.4 \mathrm{~Hz}, \mathrm{~d}), 7.48(2 \mathrm{H}, J=6 \mathrm{~Hz}, \mathrm{~d}), 7.62(4 \mathrm{H}, J=8.1 \mathrm{~Hz}$, t), $7.70-7.88(10 \mathrm{H}, \mathrm{m}), 7.93(2 \mathrm{H}, J=5.4 \mathrm{~Hz}, \mathrm{~d}), 8.27(2 \mathrm{H}, J$ $=7.8 \mathrm{~Hz}, \mathrm{~d}), 8.42(6 \mathrm{H}, \mathrm{m})$.

$\left[\left\{\mathrm{Os}(\text { bpy })_{2}\right\}_{2}(\mu-d p o)\right]\left(\mathrm{PF}_{6}\right)_{3}$. [Os(bpy $\left.)_{2} \mathrm{Cl}_{2}\right] \cdot 2 \mathrm{H}_{2} \mathrm{O}(94.3 \mathrm{mg}$, $0.155 \mathrm{mmol})$ and dpo (16.8 $\mathrm{mg}, 0.0747 \mathrm{mmol})$ were dissolved in 3:1 ethanol/water $(10 \mathrm{~mL})$ and heated at reflux for $80 \mathrm{~h}$. Subsequent treatment was performed as described above: yield, $24 \mathrm{mg}$ (20\%). Diastereoisomeric separation was achieved in one pass down the cation exchange chromatography column (SP Sephadex C-25) with the rac isomer being eluted first followed by the meso (both forms were dark purple). The ${ }^{1} \mathrm{H}$ NMR spectra had similar features to their ruthenium analogues, but many of the resonances were rather broad. Concerted attempts at further purification met with limited success. The complexes were considered not sufficiently pure for elemental analysis, although the electrochemical studies indicated that they were substantially the desired complexes.

\section{Results and Discussion}

Synthesis, Diastereoisomer Separation, and Characterization. The syntheses and diastereoisomer separations of the complexes $\left[\left\{\mathrm{Ru}(\mathrm{bpy})_{2}\right\}_{2}(\mu\right.$-dpo $\left.)\right]\left(\mathrm{PF}_{6}\right)_{4},{ }^{10}\left[\left\{\mathrm{Ru}(\mathrm{bpy})_{2}\right\}_{2}\left(\mu\right.\right.$-dpi $\left.\left.{ }^{-}\right)\right]-$ $\left(\mathrm{PF}_{6}\right)_{3},{ }^{11}$ and $\left[\left\{\mathrm{Ru}(\mathrm{bpy})_{2}\right\}_{2}(\mu-\mathrm{dpb})\right]\left(\mathrm{PF}_{6}\right)_{4}{ }^{20}$ have been reported previously.

The complexes $\left[\left\{\mathrm{Os}(\mathrm{bpy})_{2}\right\}_{2}\left(\mu-\mathrm{dpi}^{-}\right)\right]\left(\mathrm{PF}_{6}\right)_{3}$ and $\left[\left\{\mathrm{Os}(\mathrm{bpy})_{2}\right\}_{2^{-}}\right.$ ( $\mu$-dpo) $]\left(\mathrm{PF}_{6}\right)_{4}$ were synthesized by reacting 2.2 equiv of cis$\left[\mathrm{Os}(\mathrm{bpy})_{2} \mathrm{Cl}_{2}\right] \cdot 2 \mathrm{H}_{2} \mathrm{O}$ with the appropriate bridging ligand using microwave and thermal methods, respectively. The separation of the diastereoisomers was achieved on a SP Sephadex C-25 cation exchange chromatography column with aqueous sodium
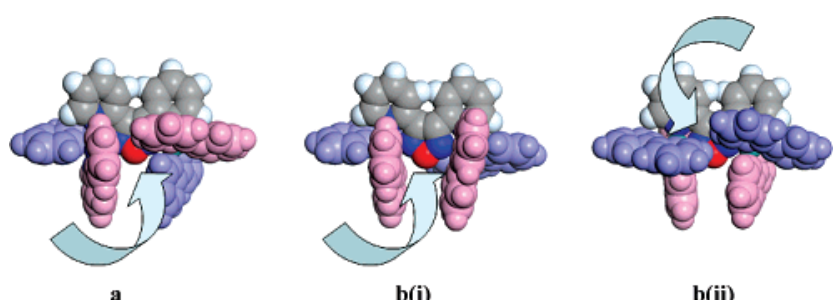

Figure 2. The (a) rac and (b) meso diastereoisomers of $\left[\left\{\mathrm{Ru}(\mathrm{bpy})_{2}\right\}_{2^{-}}\right.$ $(\mu$-dpo $)]^{4+}$, viewed perpendicularly to the plane of the bridging ligand [b(i) and b(ii) are views from opposite sides of the bridge]. In part a, the pink bpy ligands on the front side of the molecule are orthogonal to each other and are identical to the purple ligands on the back side. In part $b$, the pink ligands are parallel to each other but are not identical to the purple ligands on the opposite side, which are also parallel but nearly in line with each other. The arrows indicate the internal cavities.

toluene-4-sulfonate solution as the eluent. After rigorous purification, the ${ }^{1} \mathrm{H}$ NMR spectra of the diastereoisomers of both osmium complexes were recorded. Assignment of the peaks was made with reference to the analogous ruthenium species. ${ }^{10,11}$ For the dpi ${ }^{-}$-bridged osmium complex, the spectra for the two diastereoisomers were distinctly different, confirming a successful separation, as demonstrated by the resonances for the proton on the imidazolate ring for the meso and rac forms at 5.34 and $5.71 \mathrm{ppm}$, respectively. The spectra are shown in Figure S1 of the Supporting Information.

The dpo-bridged osmium complex proved rather intransigent in terms of the purification and characterization. Although cation exchange chromatography separated the complex into two clear bands - presumably the two diastereoisomers-the ${ }^{1} \mathrm{H}$ NMR of the two isolated products showed significant peak-broadening. This feature persisted after sustained attempts of further purification by crystallization and chromatography, although it could arise from conformational isomerism, as described previously for $\left[\left\{\operatorname{Ru}(\mathrm{bpy})_{2}\right\}(\mu-2,3-\mathrm{dpp})\left\{\mathrm{Ru}(\mathrm{phen})_{2}\right]^{4+}\{2,3-\mathrm{dpp}=2,3-\right.$ bis(2-pyridyl)pyrazine; phen $=1,10$-phenanthroline $\}.{ }^{27}$ The electrochemistry data were sufficiently promising to persevere, although two small redox processes were observed in addition to those confidently assigned to the $[5+/ 4+]$ and $[6+/ 5+]$ oxidations of desired complex that corresponded to the major component in the sample. This issue was not resolved and may be due to an unknown decomposition of the coordinated ligand.

The formation of cavities above and below the bridging ligand and bounded by the terminal ligands in dinuclear species of this type has been discussed in detail previously. ${ }^{8,9,26,27} \mathrm{Di}$ bidentate bridging ligands can be categorized as linear, ${ }^{8,27}$ angular, ${ }^{9}$ or stepped-parallel ${ }^{28}$ on the basis of the relative disposition of the bidentate coordination sites: both the dpo and $\mathrm{dpi}^{-}$ligands used in the present study are angular. The cavities allow the complexes to act as hosts for guest anions and/or solvent molecules in solution: ${ }^{8,18}$ differential solvent and anion association may occur between the diastereoisomers due to the differences in their shape and dimensions. This provides the opportunity to exploit the stereoisomeric forms of these dinuclear species as a means of investigating outer sphere effects on inter-metal electronic coupling via the studies of the IVCT transition.

In the present case, for the structurally similar "angular" bridges dpo and $\mathrm{dpi}^{-}$, the two diastereoisomeric forms present quite different spatial alternatives to the anion, as shown in Figure 2. ${ }^{27}$ The rac isomer has only one kind of cavity (both above and below the bridge) which is reasonably large and nonspecific (Figure 2a). On the other hand, the meso isomer has two differently shaped interior cavities: one of them [Figure $2 b(i)\}$ has two bpy ligands parallel and well separated from 
TABLE 1: Electrochemical Data in Acetonitrile Solution for Both Diastereoisomers of $\left[\left\{\operatorname{Ru}(b p y)_{2}\right\}_{2}\left(\mu \text {-dpi }^{-}\right)\right]^{3+}\left(\mathbf{R u}_{-d p i^{-}}\right)$, $\left[\left\{\mathrm{Os}(\mathrm{bpy})_{2}\right\}_{2}\left(\mu \text {-dpi }^{-}\right)\right]^{3+}\left(\mathrm{Os}-\mathrm{dpi}{ }^{-}\right),\left[\left\{\mathrm{Ru}(\mathrm{bpy})_{2}\right\}_{2}(\mu \text {-dpo })\right]^{4+}(\mathrm{Ru}-\mathrm{dpo})$, and $\left[\left\{\mathrm{Os}(\mathrm{bpy})_{2}\right\}_{2}(\mu \text {-dpo })\right]^{4+}($ Os-dpo): All Redox Potentials Are Determined from SWV and Are Quoted to $\pm 3 \mathrm{mV}$ against $\left[\mathrm{Fe}(\mathrm{Cp})_{2}\right]^{+/ 0}$

\begin{tabular}{|c|c|c|c|c|c|c|c|c|c|}
\hline \multirow[b]{3}{*}{ cation } & \multirow[b]{3}{*}{$\begin{array}{l}\text { supporting } \\
\text { electrolyte }^{a}\end{array}$} & \multicolumn{8}{|c|}{ diastereoisomer } \\
\hline & & \multicolumn{4}{|c|}{ meso } & \multicolumn{4}{|c|}{$\mathrm{rac}$} \\
\hline & & $K_{\mathrm{c}}$ & $\begin{array}{l}\Delta E_{\mathrm{ox}} \\
\mathrm{mV}\end{array}$ & $\begin{array}{l}E_{\mathrm{ox} 2} \\
\mathrm{mV}\end{array}$ & $\begin{array}{l}E_{\mathrm{ox} 1} \\
\mathrm{mV}\end{array}$ & $K_{\mathrm{c}}$ & $\begin{array}{c}\Delta E_{\mathrm{ox}} \\
\mathrm{mV}\end{array}$ & $\begin{array}{l}E_{\mathrm{ox} 2} \\
\mathrm{mV}\end{array}$ & $\begin{array}{l}E_{\mathrm{ox} 1} \\
\mathrm{mV}\end{array}$ \\
\hline Ru-dpo & $\mathrm{PF}_{6}{ }^{-} / 0.1 \mathrm{M}$ & $1.2 \times 10^{5}$ & 360 & 1536 & 1176 & $4.8 \times 10^{5}$ & 336 & 1536 & 1200 \\
\hline Os-dpo & $\mathrm{PF}_{6}{ }^{-} / 0.1 \mathrm{M}$ & $1.3 \times 10^{7}$ & 420 & 970 & 550 & $1.5 \times 10^{7}$ & 424 & 976 & 552 \\
\hline Ru-dpi ${ }^{-}$ & $\mathrm{PF}_{6}-/ 0.1 \mathrm{M}$ & $6.5 \times 10^{5}$ & 344 & 884 & 550 & $1.9 \times 10^{5}$ & 312 & 844 & 532 \\
\hline Os-dpi- & $\mathrm{PF}_{6}^{-} / 0.1 \mathrm{M}$ & $3.8 \times 10^{3}$ & 212 & 376 & 164 & $2.1 \times 10^{3}$ & 196 & 364 & 168 \\
\hline Ru-dpi- & $\left\{\mathrm{B}\left(\mathrm{C}_{6} \mathrm{~F}_{5}\right)_{4}\right\}^{-} / 0.02 \mathrm{M}$ & $7.3 \times 10^{5}$ & 347 & 931 & 584 & $7.9 \times 10^{5}$ & 349 & 941 & 592 \\
\hline Os-dpi ${ }^{-}$ & $\left\{\mathrm{B}\left(\mathrm{C}_{6} \mathrm{~F}_{5}\right)_{4}\right\}^{-} / 0.02 \mathrm{M}$ & $6.1 \times 10^{3}$ & 224 & 428 & 204 & $5.2 \times 10^{3}$ & 220 & 428 & 208 \\
\hline
\end{tabular}

${ }^{a}$ Cation is $\left[n-\left(\mathrm{C}_{4} \mathrm{H}_{9}\right)_{4} \mathrm{~N}\right]^{+}$in all cases.

each other where aromatic anions may associate by $\pi$-stacking or hydrophobic interaction, ${ }^{26}$ and the cavity on the opposite side of the bridge [Figure 2b(ii)] consists of parallel ligands that are almost in line with each other, to which anions may have considerably less access. The exterior cavities made by the terminal ligands are identical in the diastereoisomers. ${ }^{27}$

Nature of the Bridging Ligands-Electrochemical Studies. The comparison of neutral and anionic bridges in terms of their mediation of the coupling between the two metal centers in dinuclear species has been discussed previously. ${ }^{12,13}$ In the present instance, the electrochemical behavior of the diruthenium and di-osmium complexes of the bridges dpo (neutral) and $\mathrm{dpi}^{-}$(anionic) was investigated on the basis of the very close structural relationship of the respective species.

Electrochemical studies were undertaken on $1 \mathrm{mM}$ solutions of both diastereoisomers of $\left[\left\{\mathrm{M}(\mathrm{bpy})_{2}\right\}_{2}\left(\mu-\mathrm{dpi}^{-}\right)\right]^{3+}\left(\mathrm{M}-\mathrm{dpi}{ }^{-}\right)$ and $\left[\left\{\mathrm{M}(\mathrm{bpy})_{2}\right\}_{2}(\mu \text {-dpo })\right]^{4+}(\mathrm{M}$-dpo) (where $\mathrm{M}=\mathrm{Ru}$, Os) in acetonitrile/0.1 M $\left[n-\left(\mathrm{C}_{4} \mathrm{H}_{9}\right)_{4} \mathrm{~N}\right] \mathrm{PF}_{6}$ solution and in the case of the dpi ${ }^{-}$-bridged complexes in acetonitrile/0.02 $\mathrm{M}\left[n-\left(\mathrm{C}_{4} \mathrm{H}_{9}\right)_{4} \mathrm{~N}\right]-$ $\left\{\mathrm{B}\left(\mathrm{C}_{6} \mathrm{~F}_{5}\right)_{4}\right\}$ solution. The redox potentials for the metal-based oxidations ( $E_{\mathrm{ox} 1}$ and $E_{\mathrm{ox} 2}$ ), the separation between those potentials $\left(\Delta E_{\mathrm{ox}}\right)$, and the comproportionation constants, $K_{\mathrm{c}}$ calculated from $\Delta E_{\text {ox }}$ (eq 2) are shown in Table 1.

Each complex showed two reversible one-electron oxidations that correspond to the successive oxidation of the metal centers $\left(E_{\mathrm{ox} 1}\right.$ for the $[5+/ 4+]$ couple, $E_{\mathrm{ox} 2}$ for the $[6+/ 5+]$ couple for M-dpo, and the $[4+/ 3+]$ and $[5+/ 4+]$ couples, respectively, for $\mathrm{M}-\mathrm{dpi}^{-}$). For each bridging ligand, the metal-based oxidations in the ruthenium complexes occur at characteristically higher potentials (more anodic) than in their osmium analogues. ${ }^{29}$

For the dpo- and the $\mathrm{dpi}^{-}$-bridged dinuclear ruthenium and osmium complexes in acetonitrile/[ $\left.n-\left(\mathrm{C}_{4} \mathrm{H}_{9}\right)_{4} \mathrm{~N}\right] \mathrm{PF}_{6}$ solution, the meso diastereoisomer had a larger value of $\Delta E_{\mathrm{ox}}$ (and $K_{\mathrm{c}}$ ) than the respective rac form. Although there may be an inherent stereochemical effect brought about by alignments of $\pi$-systems and/or reorganizational energies, there will also be a contribution from differential anion association because of the nature of the interior cavities.

The oxidations for the dpo-bridged complexes occurred at higher potentials (more anodically) than the dpi--bridged analogues: this is an electrostatic effect as the unoxidized dpi ${ }^{-}$bridged species has an overall $3+$ charge, whereas the dpobridged species has a $4+$ charge, making the latter intrinsically more difficult to oxidize and thus increasing the potential.

For both ruthenium complexes, the $\Delta E_{\mathrm{ox}}$ (and therefore $K_{\mathrm{c}}$ ) values are very large, indicating there is significant electronic coupling under these conditions (with the dpo-bridged complex being slightly higher). However, in the case of osmium, although the dpo-bridged osmium species have very large $\Delta E_{\mathrm{ox}}\left(\right.$ and $K_{\mathrm{c}}$ ) values, they are significantly lower for the $\mathrm{dpi}^{-}$-bridged

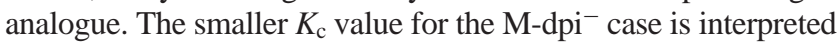
as being a consequence of the $\pi$-donor nature of the anionic bridge and the resultant preference for a hole transfer (rather than an electron transfer) mechanism for valence exchange. ${ }^{12}$

The alternate mechanisms that operate in charge transfer in the dpo- and $\mathrm{dpi}^{-}$-bridged complexes (electron and hole transfer, respectively) are expected to differently affect the relative responses of $K_{\mathrm{c}}$ between analogous ruthenium and osmium complexes: ${ }^{12,13}$ the osmium mixed-valence complexes have an increased $K_{\mathrm{c}}$ in the case of electron transfer but a decreased $K_{\mathrm{c}}$ for the hole transfer relative to their ruthenium analogues. In the case of the $\pi$-acceptor bridge dpo with two metal centers, the metal centers back-donate electrons into the acceptor LUMO of the ligand: ${ }^{12}$ removal of an electron from one of the metalcentered orbitals increases the donation of electrons to the LUMO of the ligand from the other metal center (mediated through the $\pi$-system of the ligand) making the redox potential higher for the second metal oxidation. Osmium has stronger $\pi$-donating abilities than ruthenium and $K_{\mathrm{c}}$ is therefore higher for osmium complexes $\left[1.3 \times 10^{7}\right.$ (meso) and $1.5 \times 10^{7}(\mathrm{rac})$ for osmium, compared with $1.2 \times 10^{6}$ and $4.8 \times 10^{5}$ for the respective diastereoisomers of ruthenium]. In the case of a $\pi$-donor bridge such as $\mathrm{dpi}^{-}$, the opposite argument applies. The metal centers in this case are accepting electrons from the donating HOMO of the ligand: ${ }^{12}$ removal of an electron from one of the metal-centered orbitals increases the donation from the HOMO to that center, removing electron density from the other, thus making the redox potential higher for the second metal oxidation. Osmium is a weaker $\pi$-acceptor than ruthenium; the magnitude of this effect will be less, and $K_{\mathrm{c}}$ should be lower for osmium complexes in a hole transfer situation [3800 (meso) and $2100(\mathrm{rac})$ for the osmium diastereoisomers and $6.5 \times 10^{5}$ and $1.9 \times 10^{5}$ for the respective ruthenium complexes in acetonitrile/[n-( $\left.\left.\mathrm{C}_{4} \mathrm{H}_{9}\right)_{4} \mathrm{~N}\right] \mathrm{PF}_{6}$ solution]. The same trend holds for the complexes in acetonitrile/ $\left[n-\left(\mathrm{C}_{4} \mathrm{H}_{9}\right)_{4} \mathrm{~N}\right]\left\{\mathrm{B}\left(\mathrm{C}_{6} \mathrm{~F}_{5}\right)_{4}\right\}$ solution.

Anion-Association Studies. Determination of the LeastAssociating Electrolyte. The degree of inter-metal electron coupling or valence delocalization for a given dinuclear complex is often qualitatively assessed from the difference between the redox potentials $\Delta E_{\mathrm{ox}}$ for the successive oxidations $\mathrm{M}_{1}{ }^{\mathrm{II}} \mathrm{M}_{2}{ }^{\mathrm{II}} \rightarrow$ $\mathrm{M}_{1}{ }^{\mathrm{II}} \mathrm{M}_{2}{ }^{\mathrm{III}}$ and $\mathrm{M}_{1}{ }^{\mathrm{II}} \mathrm{M}_{2}{ }^{\mathrm{III}} \rightarrow \mathrm{M}_{1}{ }^{\mathrm{III}} \mathrm{M}_{2}{ }^{\mathrm{III}},{ }^{30}$ which can in turn be used to calculate the comproportionation constant $\left(K_{\mathrm{c}}\right)$, as given in eq 2 .

However, the value of $\Delta E_{\mathrm{ox}}$ is known to be influenced by the presence of anions in the electrolyte in which such electrochemical measurements are made: under "nonassociating" electrolyte conditions, the $\Delta E_{\mathrm{ox}}$ value is at its greatest but will be diminished when there is strong association between an anion and the dinuclear complex. ${ }^{19,30,31}$ The presence of an anion 
TABLE 2: Electrochemical Data for $\left[\left\{\operatorname{Ru}(b p y)_{2}\right\}_{2}(\mu \text {-dpb })\right]^{n+}$ Against $\left[\mathrm{Fe}(\mathrm{Cp})_{2}\right]^{+/ 0}$ in Acetonitrile Solution: All Redox Potentials Are Quoted to $\pm \mathbf{3} \mathbf{~ m V}$

\begin{tabular}{|c|c|c|c|c|c|c|c|c|}
\hline \multirow[b]{3}{*}{$\begin{array}{l}\text { supporting } \\
\text { electrolyte }\end{array}$} & \multicolumn{8}{|c|}{ diastereoisomers of $\left[\left\{\mathrm{Ru}(\mathrm{bpy})_{2}\right\}_{2}(\mu-\mathrm{dpb})\right]^{n+}$} \\
\hline & \multicolumn{4}{|c|}{ meso } & \multicolumn{4}{|c|}{$\mathrm{rac}$} \\
\hline & $K_{\mathrm{c}} \times 10^{-3}$ & $\begin{array}{c}\Delta E_{\mathrm{ox}} \\
\mathrm{mV}\end{array}$ & $\begin{array}{l}E_{\mathrm{ox} 2} \\
\mathrm{mV}\end{array}$ & $\begin{array}{l}E_{\text {ox1 }} \\
\mathrm{mV}\end{array}$ & $K_{\mathrm{c}} \times 10^{-3}$ & $\begin{array}{c}\Delta E_{\mathrm{ox}} \\
\mathrm{mV}\end{array}$ & $\begin{array}{l}E_{\mathrm{ox} 2} \\
\mathrm{mV}\end{array}$ & $\begin{array}{l}E_{\text {ox1 }} \\
\mathrm{mV}\end{array}$ \\
\hline$\left[\left(n-\mathrm{C}_{4} \mathrm{H}_{9}\right)_{4} \mathrm{~N}\right] \mathrm{PF}_{6} / 0.1 \mathrm{M}$ & 2.4 & 200 & 1291 & 1091 & 1.3 & 184 & 1295 & 1111 \\
\hline $\mathrm{Cs}\left(\mathrm{CB}_{11} \mathrm{H}_{6} \mathrm{Br}_{6}\right) / 0.1 \mathrm{M}$ & 4.5 & 216 & 1341 & 1125 & 2.2 & 198 & 1333 & 1135 \\
\hline$\left[\left(n-\mathrm{C}_{4} \mathrm{H}_{9}\right)_{4} \mathrm{~N}\right]\left\{\mathrm{B}\left(\mathrm{C}_{6} \mathrm{~F}_{5}\right)_{4}\right\} / 0.02 \mathrm{M}$ & 5.2 & 220 & 1376 & 1156 & 2.8 & 204 & 1372 & 1168 \\
\hline
\end{tabular}

that associates into the cavities above and below the bridging ligand of the complex cation reduces the average charge of the ion-pair relative to the nonassociating case, so both oxidations are more easily performed and both are shifted cathodically. Once the first oxidation has occurred, ion-pairing will then be stronger for electrostatic reasons, resulting in a larger shift of $E_{\mathrm{ox} 2}$ and thus reducing $\Delta E_{\mathrm{ox}}$. Therefore, in principle, because a large $\Delta E_{\mathrm{ox}}$ is associated with delocalization, the presence of anions enhances the localization of the charges in the mixedvalence species.

To probe this effect, it was necessary to establish a "baseline" electrolyte for which there was minimal association. Reed et al. ${ }^{24,32,33}$ have championed a series of icosahedral carborane anions as the lowest coordinating anions, and Geiger and coworkers ${ }^{21}$ have proposed the use of the tetrakis(pentafluorophenyl)borate anion $\left\{\mathrm{B}\left(\mathrm{C}_{6} \mathrm{~F}_{5}\right)_{4}\right\}^{-}$in the same context. We undertook the electrochemistry (CV and SWV) of the diastereoisomers of the complex $\left[\left\{\mathrm{Ru}(\mathrm{bpy})_{2}\right\}_{2}(\mu \text {-dpb })\right]^{4+}[\mathrm{dpb}=2,3$-bis(2-pyridyl)quinoxaline] in acetonitrile solution using $0.1 \mathrm{M} \mathrm{Cs}\left(\mathrm{CB}_{11} \mathrm{H}_{6^{-}}\right.$ $\left.\mathrm{Br}_{6}\right)$ and $0.02 \mathrm{M}\left[\left(n-\mathrm{C}_{4} \mathrm{H}_{9}\right)_{4} \mathrm{~N}\right]\left\{\mathrm{B}\left(\mathrm{C}_{6} \mathrm{~F}_{5}\right)_{4}\right\}^{34}$ as the electrolytes. The ferrocene/ferrocenium couple $\left(\left[\mathrm{Fe}(\mathrm{Cp})_{2}\right]^{+/ 0}\right)$ was used as an internal reference for these studies and added upon completion of each experiment. Although this couple is known to be solvent- and electrolyte-dependent, ${ }^{35}$ we have shown ${ }^{19}$ that in the electrolytic conditions used in these studies there is little difference between it and the redox couple $\left[\mathrm{Fe}\left(\mathrm{Me}_{5} \mathrm{Cp}\right)_{2}\right]^{+/ 0}{ }^{36}$ which is known to be less susceptible to the environment. The results for the electrochemistry are shown in Table 2, along with a comparison for data obtained using acetonitrile/0.1 M $\left[\left(n-\mathrm{C}_{4} \mathrm{H}_{9}\right)_{4} \mathrm{~N}\right] \mathrm{PF}_{6}$.

Both diastereoisomers of $\left[\left\{\mathrm{Ru}(\mathrm{bpy})_{2}\right\}_{2}(\mu \text {-dpb })\right]^{n+}$ were observed to have lower potentials $E_{\mathrm{ox} 1}$ and $E_{\mathrm{ox} 2}$ with the carborane than with the tetrakis(pentafluorophenyl)borate electrolyte (although the respective $\Delta E_{\mathrm{ox}}$ values in the two electrolytes for each of the diastereoisomers are within experimental uncertainty). These results suggest that perfluorinated-tetraphenylborate is the more weakly associating of the two anions under these specific conditions, and accordingly, $0.02 \mathrm{M}\left[\left(n-\mathrm{C}_{4} \mathrm{H}_{9}\right)_{4} \mathrm{~N}\right]-$ $\left\{\mathrm{B}\left(\mathrm{C}_{6} \mathrm{~F}_{5}\right)_{4}\right\}$ was chosen as the base electrolyte for use in these studies.

Spectroelectrochemical Studies of the Complex $[\{\mathrm{Ru}-$ (bpy $\left.)_{2}\right\}_{2}\left(\boldsymbol{\mu}\right.$-dpi $\left.\left.\mathbf{i}^{-}\right)\right]^{n+}$. Spectrochemical investigations were performed at $25^{\circ} \mathrm{C}$ on $0.5 \mathrm{mM}$ solutions of both diastereoisomers of $\left[\left\{\mathrm{Ru}(\mathrm{bpy})_{2}\right\}_{2}\left(\mu-\mathrm{dpi}^{-}\right)\right]^{3+}$ over the UV/visible/NIR spectral range in acetonitrile solution containing $0.02 \mathrm{M}\left[\left(n-\mathrm{C}_{4} \mathrm{H}_{9}\right)_{4} \mathrm{~N}\right] \mathrm{X}$, where $\mathrm{X}$ denotes $\mathrm{B}\left(\mathrm{C}_{6} \mathrm{~F}_{5}\right)_{4}{ }^{-}$, toluene-4-sulfonate, or a mixture of the two (and maintaining constant ionic strength). The toluene-4-sulfonate anion is known to very strongly associate to complexes of this genre (a fact that is exploited in the separation of the diastereoisomers). ${ }^{19,25,26}$

The spectra for the diastereoisomers of $\left[\left\{\mathrm{Ru}(\mathrm{bpy})_{2}\right\}_{2}(\mu\right.$ $\left.\left.\mathrm{dpi}^{-}\right)\right]^{n+}$ have been reported previously. ${ }^{11}$ The spectral features of the $3+$ species were assigned as a combination of overlapping $\mathrm{d} \pi\left(\mathrm{Ru}^{\mathrm{II}}\right) \rightarrow \pi^{*}\left(\mathrm{dpi}^{-}\right)$and $\mathrm{d} \pi\left(\mathrm{Ru}^{\mathrm{II}}\right) \rightarrow \pi^{*}($ bpy) metal-to-ligand charge transfer (MLCT) transitions. Oxidation to the $4+$ species was distinguished by the appearance of an intense band in the region from 3300 to $8000 \mathrm{~cm}^{-1}$ (the lower energy side was obscured by the detector limit), which was assigned as the IVCT band. A less intense band appeared in the region 8000-15 000 $\mathrm{cm}^{-1}$, which was assigned as a ligand-to-metal charge-transfer (LMCT) band. The appearances of the new bands were accompanied by a $\sim 50 \%$ reduction in the intensity of the MLCT bands, which is attributed to the conversion of one of the centers from $\mathrm{Ru}^{\mathrm{II}}$ to $\mathrm{Ru}^{\mathrm{III}}$. On returning to the $3+$ species, the IVCT and LMCT bands completely collapsed, and the MLCT bands returned to their original intensity. Isosbestic points generally remained stable on generating the $4+$ species and on returning to the $3+$ species, with the starting spectrum being regenerated to $\sim 95 \%$ for both diastereoisomers under all the electrolyte conditions.

As the IVCT band for $\left[\left\{\mathrm{Ru}(\mathrm{bpy})_{2}\right\}_{2}\left(\mu-\mathrm{dpi}^{-}\right)\right]^{4+}$ appeared in the region of the detector limit, a full analysis of the IVCT band was difficult. Nevertheless, a semiquantitative analysis could be made with regard to the effect of the anion: an overlay of the IVCT bands for $\left[\left\{\mathrm{Ru}(\mathrm{bpy})_{2}\right\}_{2}\left(\mu-\mathrm{dpi}^{-}\right)\right]^{4+}$ with different electrolytes is provided in Figure S2 (Supporting Information), where the spectral data are plotted as the reduced form of $\int \epsilon / v \mathrm{~d} v$ vs $\nu$. The bandwidth $\Delta v_{1 / 2}$ was taken at half the band maximum $v_{\max }$, and the theoretical bandwidth $\Delta v_{1 / 2}{ }^{\circ}$ was calculated from eq $3,{ }^{37,38}$ where the reorganizational energy $(\lambda$ $=\lambda_{\mathrm{i}}+\lambda_{\mathrm{o}}$ ) is assumed to be equal to $v_{\max }, R$ is the gas constant, and the term $16 R T=2310 \mathrm{~cm}^{-1}$ at $298 \mathrm{~K}$.

$$
\Delta v_{1 / 2}^{\circ}=[16 R T \ln 2(\lambda)]^{1 / 2}=\left[16 R T \ln 2\left(v_{\max }\right)\right]^{1 / 2}
$$

Brunschwig, Creutz, and Sutin ${ }^{39}$ have introduced a parameter $\Gamma$ based upon the experimental and predicted IVCT bandwidths, given in eq 4 , which attempts to provide a measure of the electronic coupling in mixed-valence systems. The magnitude of $\Gamma$ distinguishes the class ${ }^{40}$ of a mixed-valence system: $0<$ $\Gamma<0.1$ for weakly coupled (localized) Class II systems, $0.1<$ $\Gamma<0.5$ for moderately coupled (localized) Class II systems, $\Gamma$ $\sim 0.5$ at the transition between Class II and Class III, and $\Gamma>$ 0.5 for strongly coupled (delocalized) Class III systems. Although the measure is only semiquantitative, it is consistent with the findings of a variety of physical techniques for a range of complexes: ${ }^{27}$ it provides a reasonable assessment of the coupling for mixed-valence systems between the localized and delocalized limits, although band shape analyses may frequently be complicated by a number of factors. ${ }^{41}$

$\Gamma=1-\left(\Delta v_{1 / 2}\right) /\left[16 R T \ln (2) v_{\max }\right]^{1 / 2}=1-\left(\Delta v_{1 / 2}\right) /\left(\Delta v_{1 / 2}{ }^{0}\right)$

For the present case of $\mathrm{Ru}^{-\mathrm{dpi}}{ }^{-}$, the results for the band maxima $\left(\nu_{\max }\right)$, the molar absorption coefficients $\left(\epsilon / \nu_{\max }\right)$, the (pseudo) bandwidths, and the electronic coupling factor $\Gamma$ are shown in Table 3. 
TABLE 3: NIR Spectral Data of the Reduced Absorption Spectra for the High-Energy Side of the IVCT Manifold of $\left[\left\{\operatorname{Ru}(\mathrm{bpy})_{2}\right\}_{2}\left(\mu-\mathrm{dpi}^{-}\right)\right]^{4+}$

\begin{tabular}{ccccccc}
\hline $\begin{array}{c}\left.\mathrm{Tos}^{-}\right]^{a} \\
\%\end{array}$ & diastereoisomer & $\begin{array}{c}v_{\max }{ }^{b} \\
\mathrm{~cm}^{-1}\end{array}$ & $\begin{array}{c}\epsilon / \nu_{\max } \\
\mathrm{M}^{-1}\end{array}$ & $\begin{array}{c}\Delta v_{1 / 2} \\
\mathrm{~cm}^{-1}\end{array}$ & $\begin{array}{c}\Delta \nu_{1 / 2}{ }^{\circ} \\
\mathrm{cm}^{-1}\end{array}$ & $\Gamma$ \\
\hline 0 & rac & 3300 & 1.091 & 2080 & 2760 & 0.25 \\
& meso & 3300 & 0.767 & 1930 & 2760 & 0.30 \\
10 & rac & 3300 & 0.485 & 2130 & 2760 & 0.23 \\
& meso & 3300 & 0.448 & 2050 & 2760 & 0.26 \\
25 & rac & 3300 & 0.671 & 2180 & 2760 & 0.21 \\
& meso & 3300 & 0.532 & 2090 & 2760 & 0.24 \\
50 & rac & 3300 & 0.722 & 2200 & 2760 & 0.20 \\
& meso & 3300 & 0.573 & 2110 & 2760 & 0.24 \\
100 & rac & 3300 & 0.775 & 2210 & 2760 & 0.20 \\
& meso & 3300 & 0.749 & 2130 & 2760 & 0.23
\end{tabular}

${ }^{a}$ The concentration of toluene-4-sulfonate as a percentage of 0.02 $\left.\mathrm{M}\left[\left(n-\mathrm{C}_{4} \mathrm{H}_{9}\right) \mathrm{N}\right)_{4}\right] \mathrm{X}$ where $\left\{\mathrm{B}\left(\mathrm{C}_{6} \mathrm{~F}_{5}\right)_{4}\right\}^{-}$makes up the remainder. ${ }^{b}$ Due to the cutoff at the detector limit, $v_{\max }$ was taken as $3300 \mathrm{~cm}^{-1}$

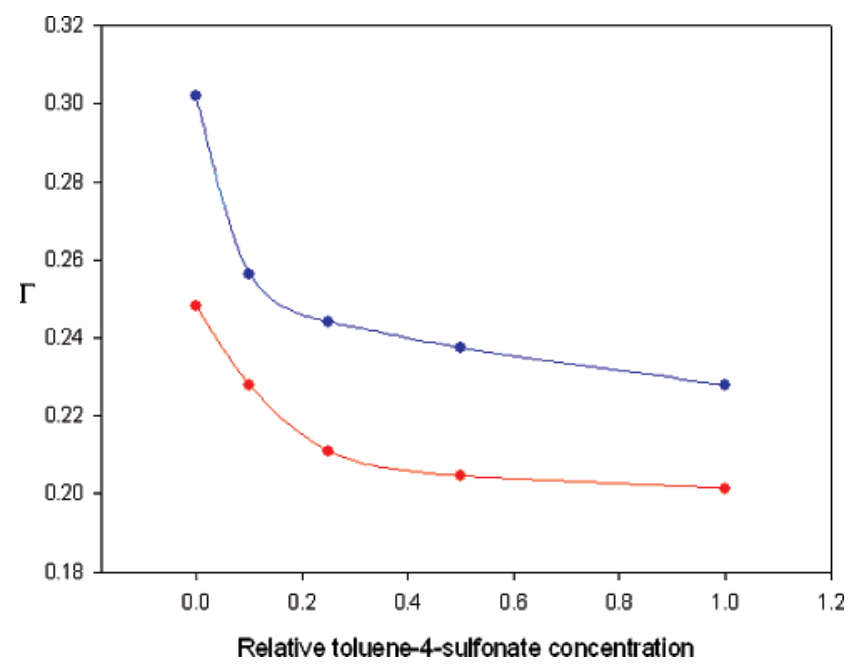

Figure 3. The $\Gamma$ parameter for meso (blue) and rac (red) diastereoisomers of $\left[\left\{\mathrm{Ru}(\mathrm{bpy})_{2}\right\}_{2}\left(\mu-\mathrm{dpi}^{-}\right)\right]^{4+}$ from spectroelectrochemical measurements in acetonitrile solution as a function of the $\left[\left(n-\mathrm{C}_{4} \mathrm{H}_{9}\right)_{4} \mathrm{~N}\right]-$ (toluene-4-sulfonate) $/\left[\left(n-\mathrm{C}_{4} \mathrm{H}_{9}\right)_{4} \mathrm{~N}\right]\left\{\mathrm{B}\left(\mathrm{C}_{6} \mathrm{~F}_{5}\right)_{4}\right\}$ electrolyte ratio.

The values of $\Gamma$ suggest that these complexes should be classified as Class II. ${ }^{40}$ For each electrolyte condition, the rac isomer had a lower value of $\Gamma$ than did the meso isomer, suggesting that it is slightly more localized.

Figure 3 presents a graph of the $\Gamma$ parameter for each diastereoisomer as a function of the relative toluene-4-sulfonate concentration.

The data show that increasing the concentration of toluene4-sulfonate progressively decreases the delocalization for both diasteroisomers and therefore presumably the inter-metal electronic coupling: it is possible that association of an increasing number of ions about the species may distort the electron density to produce this effect. There is an apparent saturation at $\sim 25 \%$ relative toluene-4-sulfonate concentration, at which point there are $\sim 10$ toluene-4-sulfonate anions to every complex ion: this may be the upper limit of the number of anions that can fit around the complex cation, either spatially or electrostatically (or a combination of both).

Another very interesting feature of the plots is the change in $\Gamma$ for each diastereoisomer. For the rac form, there is a drop of 0.05 in $\Gamma$ from the maximum value (no toluene-4-sulfonate) to the saturation point, and the drop is rather steady before saturation. On the other hand, with the meso isomer, the magnitude of the drop is 0.07 , and the decrease is much sharper between 0 and $10 \%$ toluene-4-sulfonate concentration than is the case with the rac isomer. This indicates that the localization in the meso isomer is affected to a greater degree by addition of associating anions than is the rac isomer. These observations can be rationalized in terms of the size of the interior clefts of each isomer. In the meso form, one of the cavities is of the appropriate proportions for an aromatic anion such as toluene4-sulfonate to intercalate between the bpy ligands due to $\pi$-stacking/hydrophobicity, thus distorting the $\pi$-system and decreasing inter-metal communication. In the rac isomer, the cavity is larger and rather more open, so that the presence of the anion(s) has a less direct effect. This difference in cavity sizes is probably also the reason why the meso curve begins to saturate more quickly than the rac: the former only needs one or two very closely associating (or $\pi$-stacking) anions to depress the communication, and the latter needs more to produce the same level of depression as the anions are not as close or the interaction does not have such spatial restraints.

Electrochemical Studies of the Complex $\left[\left\{\operatorname{Ru}(b p y)_{2}\right\}_{2}(\mu\right.$ dpo) $]^{n+}$. Electrochemistry was performed on $1 \mathrm{mM}$ solutions of both diastereoisomers of $\left[\left\{\mathrm{Ru}(\mathrm{bpy})_{2}\right\}_{2}(\mu \text {-dpo })\right]^{4+}$ in acetonitrile containing $0.02 \mathrm{M}\left[\left(n-\mathrm{C}_{4} \mathrm{H}_{9}\right)_{4} \mathrm{~N}\right] \mathrm{X}$, where $\mathrm{X}=\mathrm{B}\left(\mathrm{C}_{6} \mathrm{~F}_{5}\right)_{4}{ }^{-}$, $\mathrm{ClO}_{4}{ }^{-}, \mathrm{PF}_{6}{ }^{-}$, and $\mathrm{BF}_{4}{ }^{-}$. The electrochemistry was also conducted in a solution containing $0.1 \mathrm{M}\left[\left(n-\mathrm{C}_{4} \mathrm{H}_{9}\right)_{4} \mathrm{~N}\right] \mathrm{PF}_{6}$ to compare the effect of electrolyte concentration on the data.

The complexes in each electrolyte solution showed two reversible one-electron oxidations, except for $0.02 \mathrm{M}[(n-$ $\left.\left.\mathrm{C}_{4} \mathrm{H}_{9}\right)_{4} \mathrm{~N}\right] \mathrm{PF}_{6}$ and $\left[\left(n-\mathrm{C}_{4} \mathrm{H}_{9}\right)_{4} \mathrm{~N}\right]\left\{\mathrm{B}\left(\mathrm{C}_{6} \mathrm{~F}_{5}\right)_{4}\right\}$ where $E_{\mathrm{ox} 2}$ was beyond the solvent breakdown. The redox potentials for the oxidations ( $E_{\mathrm{ox} 1}$ and $\left.E_{\mathrm{ox} 2}\right), \Delta E_{\mathrm{ox}}$, and the calculated comproportionation constants $K_{\mathrm{c}}$ are given in Table 4 .

The trend for $\Delta E_{\mathrm{ox}}$ (and thus for $K_{\mathrm{c}}$ ) in the rac form is $\mathrm{B}\left(\mathrm{C}_{6} \mathrm{~F}_{5}\right)_{4}{ }^{-}>\mathrm{PF}_{6}{ }^{-}>\mathrm{ClO}_{4}{ }^{-}>\mathrm{BF}_{4}{ }^{-}$; in the meso form, it is $\mathrm{B}\left(\mathrm{C}_{6} \mathrm{~F}_{5}\right)_{4}{ }^{-}>\mathrm{PF}_{6}{ }^{-}>\mathrm{BF}_{4}{ }^{-}>\mathrm{ClO}_{4}{ }^{-}$, so that the strength of the association of the anion with the respective diastereoisomers is in the reverse order for $\mathrm{BF}_{4}{ }^{-}$and $\mathrm{ClO}_{4}{ }^{-}$. The general trend follows those reported in the literature for complexes of a similar nature (including the variability of $\mathrm{ClO}_{4}{ }^{-}$). ${ }^{19}$ As described above, the meso and rac diastereoisomers experience differential association of anions between the isomers depending on the specific dimensions of the internal cavities above and below the bridging ligand and shape of the electrolyte anion.

The electrochemistry was also performed on both diastereoisomers in acetonitrile/0.1 $\mathrm{M}\left[\left(n-\mathrm{C}_{4} \mathrm{H}_{9}\right)_{4} \mathrm{~N}\right] \mathrm{PF}_{6}$. This is a standard electrolyte solution often used for electrochemical measurements, and the electrochemical data for the higher concentration solution are shown in Table 4 along with the 0.02 $\mathrm{M}\left[\left(n-\mathrm{C}_{4} \mathrm{H}_{9}\right)_{4} \mathrm{~N}\right] \mathrm{PF}_{6}$ for comparison. Although there is a difference in the ionic strength, in acetonitrile/0.02 $\mathrm{M}[(n-$ $\left.\mathrm{C}_{4} \mathrm{H}_{9}\right)_{4} \mathrm{~N}_{3} \mathrm{PF}_{6}$ solution, the first oxidation is $20 \mathrm{mV}$ more anodic than that for acetonitrile/0.1 M $\left[\left(n-\mathrm{C}_{4} \mathrm{H}_{9}\right)_{4} \mathrm{~N}\right] \mathrm{PF}_{6}$, and the second oxidation potential is beyond the limit of the solvent in the former case. The lower $K_{\mathrm{c}}$ in the latter case might be expected because of the higher anion concentration, which allows a greater level of association with the complex cation, decreasing the effective charge about the metal centers and reducing the oxidation potentials. The effect is significant: $E_{\mathrm{ox} 2}$ can be measured for both diastereoisomers with $0.1 \mathrm{M}\left[\left(n-\mathrm{C}_{4} \mathrm{H}_{9}\right)_{4} \mathrm{~N}\right]-$ $\mathrm{PF}_{6}$ as the electrolyte, whereas it is considerably anodic-in fact anodic of the solvent limit-in acetonitrile/0.02 $\mathrm{M}\left[\left(n-\mathrm{C}_{4} \mathrm{H}_{9}\right)_{4} \mathrm{~N}\right]-$ $\mathrm{PF}_{6}$ solution. These observations highlight the need for a standard set of electrolyte conditions in data used to make $K_{\mathrm{c}}$ comparisons, as noted previously by D'Alessandro and Keene. ${ }^{30}$

Spectroelectrochemical Studies of the Complex $[\{\mathbf{R u}-$ $\left.(\text { bpy })_{2}\right\}_{2}(\boldsymbol{\mu}$-dpo $\left.)\right]^{n+}$. UV/visible/NIR spectroelectrochemistry was performed on $0.5 \mathrm{mM}$ solutions of both diastereoisomers 
TABLE 4: Electrochemical Data for Each Diastereoisomer of $\left[\left\{\operatorname{Ru}(b p y)_{2}\right\}_{2}(\mu \text {-dpo })\right]^{n+}$ in Acetonitrile Containing Different Supporting Electrolytes

\begin{tabular}{|c|c|c|c|c|c|c|c|c|}
\hline \multirow[b]{3}{*}{$\begin{array}{l}\text { supporting } \\
\text { electrolyte }^{a}\end{array}$} & \multicolumn{8}{|c|}{ diastereoisomers of $\left[\left\{\mathrm{Ru}(\mathrm{bpy})_{2}\right\}_{2}(\mu \text {-dpo })\right]^{4+}$} \\
\hline & \multicolumn{4}{|c|}{ meso } & \multicolumn{4}{|c|}{ rac } \\
\hline & $K_{\mathrm{c}} \times 10^{-5}$ & $\begin{array}{l}\Delta E_{\mathrm{ox}} \\
\mathrm{mV}\end{array}$ & $\begin{array}{l}E_{\text {ox2 }} \\
\mathrm{mV}\end{array}$ & $\begin{array}{l}E_{\mathrm{ox} 1} \\
\mathrm{mV}\end{array}$ & $K_{\mathrm{c}} \times 10^{-5}$ & $\begin{array}{l}\Delta E_{\mathrm{ox}} \\
\mathrm{mV}\end{array}$ & $\begin{array}{l}E_{\mathrm{ox} 2} \\
\mathrm{mV}\end{array}$ & $\begin{array}{l}E_{\text {ox1 }} \\
\mathrm{mV}\end{array}$ \\
\hline$\left\{\mathrm{B}\left(\mathrm{C}_{6} \mathrm{~F}_{5}\right)_{4}\right\}^{-} / 0.02 \mathrm{M}$ & & & $b$ & 1240 & & & $b$ & 1288 \\
\hline $\mathrm{PF}_{6}{ }^{-} / 0.02 \mathrm{M}$ & & & $b$ & 1192 & & & $b$ & 1220 \\
\hline $\mathrm{ClO}_{4}^{-} / 0.02 \mathrm{M}$ & 3.5 & 328 & 1504 & 1176 & 4.1 & 332 & 1512 & 1180 \\
\hline $\mathrm{BF}_{4}^{-} / 0.02 \mathrm{M}$ & 7.6 & 348 & 1528 & 1180 & 2.6 & 320 & 1540 & 1220 \\
\hline $\mathrm{PF}_{6}{ }^{-} / 0.1 \mathrm{M}$ & 1.2 & 360 & 1536 & 1176 & 4.8 & 336 & 1536 & 1200 \\
\hline
\end{tabular}

${ }^{a}$ Cation is $\left[n-\left(\mathrm{C}_{4} \mathrm{H}_{9}\right)_{4} \mathrm{~N}\right]^{+}$in all cases. ${ }^{b}$ Potential beyond the anodic limit of the solvent: as this occurs at $>1800 \mathrm{mV}, \Delta E_{\mathrm{ox}}$ will be $>500 \mathrm{mV}$. All redox potentials quoted to $\pm 3 \mathrm{mV}$ against the $\left[\mathrm{Fe}(\mathrm{Cp})_{2}\right]^{+/ 0}$.

TABLE 5: NIR Spectral Data of the Reduced Absorption Spectra for the IVCT Manifold of $\left[\left\{\operatorname{Ru}(b p y)_{2}\right\}_{2}(\mu \text {-dpo })\right]^{5+}$ (Ácetonitrile Solution)

\begin{tabular}{lllllll}
\hline $\begin{array}{c}\text { supporting } \\
\text { electrolyte } \\
\text { anion }\end{array}$ & $\begin{array}{c}\text { diaster- } \\
\text { eoisomer }\end{array}$ & $\begin{array}{c}v_{\max } \\
\mathrm{cm}^{-1}\end{array}$ & $\begin{array}{c}\epsilon / \nu_{\max } \\
\mathrm{M}^{-1}\end{array}$ & $\begin{array}{c}\Delta \nu_{1 / 2} \\
\mathrm{~cm}^{-1}\end{array}$ & $\begin{array}{c}\Delta \nu_{1 / 2}{ }^{\circ} \\
\mathrm{cm}^{-1}\end{array}$ & $\Gamma$ \\
\hline$\left\{\mathrm{B}\left(\mathrm{C}_{6} \mathrm{~F}_{5}\right)_{4}\right\}^{-} / 0.02 \mathrm{M}$ & rac & 6418 & 0.191 & 1570 & 3850 & 0.59 \\
$\mathrm{PF}_{6}-10.02 \mathrm{M}$ & meso & 6558 & 0.374 & 1590 & 3890 & 0.59 \\
& rac & 6508 & 0.493 & 1560 & 3880 & 0.60 \\
$\mathrm{PF}_{6}{ }^{-} / 0.1 \mathrm{M}$ & meso & 6625 & 0.715 & 1630 & 3910 & 0.59 \\
& rac & 6478 & 0.473 & 1580 & 3870 & 0.59 \\
$\mathrm{ClO}_{4}{ }^{-} / 0.02 \mathrm{M}$ & meso & 6626 & 0.793 & 1620 & 3910 & 0.59 \\
& rac & 6413 & 0.512 & 1580 & 3850 & 0.59 \\
$\mathrm{BF}_{4}{ }^{-} / 0.02 \mathrm{M}$ & meso & 6593 & 0.808 & 1630 & 3900 & 0.58 \\
& rac & 6457 & 0.250 & 1590 & 3860 & 0.59 \\
& meso & 6603 & 0.704 & 1640 & 3910 & 0.58 \\
& & & & & &
\end{tabular}

${ }^{a}$ Cation is $\left[n-\left(\mathrm{C}_{4} \mathrm{H}_{9}\right)_{4} \mathrm{~N}\right]^{+}$in all cases.

of $\left[\left\{\mathrm{Ru}(\mathrm{bpy})_{2}\right\}_{2}(\mu \text {-dpo })\right]^{4+}$ in acetonitrile in the same electrolyte solutions used as in the above electrochemistry studies. A general description and assignment for the spectra for $[\{\mathrm{Ru}-$ (bpy $\left.)_{2}\right\}_{2}(\mu \text {-dpo) }]^{n+}$ have been given previously. ${ }^{10}$

The analysis of the IVCT band is given in Table 5.

The class ${ }^{40}$ to which a complex belongs can be made by analysis of the IVCT band, in particular the parameter $\Gamma$ (a measure of delocalization), which is calculated (eq 4) from the deviation of the bandwidth from its theoretical value. ${ }^{39}$ When $0<\Gamma<0.5$, the complex is Class II (localized); when $\Gamma \approx$ 0.5 , the complex is Class II-III; and when $\Gamma>0.5$, the complex is Class III (delocalized). [ $\left\{\mathrm{Ru}(\mathrm{bpy})_{2}\right\}_{2}(\mu$-dpo $\left.)\right]^{5+}$ is thus categorized as delocalized with $\Gamma \approx 0.6$ : as such, the IVCT may best be regarded as a transition of an electron from a delocalized molecular orbital to a higher energy delocalized molecular orbital $\left(\pi \rightarrow \pi^{*}\right)$. In the dpo-bridged complexes, the oxidation state of the mixed-valence species is therefore better represented as $\mathbf{M}_{1}^{\mathrm{II}(1 / 2)} \mathbf{M}_{2}^{\mathrm{II}(1 / 2)}$ rather than $\mathrm{M}_{1}^{\mathrm{II}} \mathbf{M}_{2}^{\mathrm{III}}$.

The $\Gamma$ values for each of the diastereoisomers show very little change with variation of the electrolytes: over the range of anions, for the rac and meso diastereoisomers, $\Gamma$ varies by 0.01 . The $\Gamma$ data are presented in Figure 4 and indicate that neither anion association or the stereochemical identity of the complex are a determinant in the extent of delocalization. As a qualitative comparison, the differences between the $\Gamma$ values for the analogous dpi ${ }^{-}$-bridged species between $\left[\left(n-\mathrm{C}_{4} \mathrm{H}_{9}\right)_{4} \mathrm{~N}\right]\left\{\mathrm{B}\left(\mathrm{C}_{6} \mathrm{~F}_{5}\right)_{4}\right\}$ and $\left[\left(n-\mathrm{C}_{4} \mathrm{H}_{9}\right)_{4} \mathrm{~N}\right]($ toluene-4-sulfonate) reported above were larger-viz. 0.05 for the rac isomer and 0.07 for the meso isomer. The increased effect of the $\left[\left(n-\mathrm{C}_{4} \mathrm{H}_{9}\right)_{4} \mathrm{~N}\right]$ (toluene-4-sulfonate) may well be due to its capacity for specific $\pi$-stacking and hydrophobic interactions in the cavities, ${ }^{25}$ an effect that is considerably enhanced with the meso isomer.

Comparison of Spectroelectrochemical and Electrochemical Methods. The parameters $\Gamma$ and $\Delta E_{\mathrm{ox}}$, derived respectively
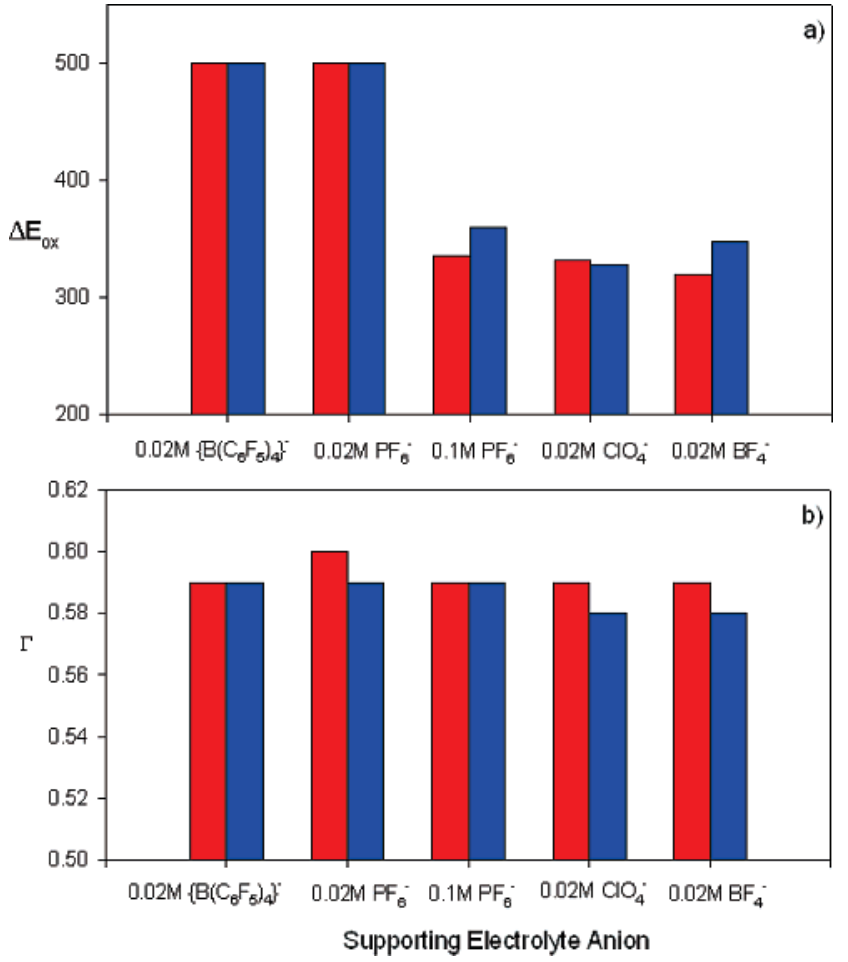

Figure 4. $\Delta E_{\mathrm{ox}}$ (a) and the $\Gamma$ parameter (b) for the rac (red) and meso (blue) diastereoisomers of $\left[\left\{\mathrm{Ru}(\mathrm{bpy})_{2}\right\}_{2}(\mu \text {-dpo })\right]^{5+}$ in different electrolyte conditions. The countercation in the solutions is $\left[\left(n-\mathrm{C}_{4} \mathrm{H}_{9}\right)_{4} \mathrm{~N}\right]^{+}$.

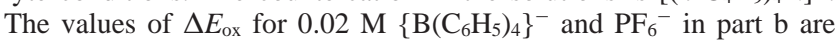
lower limits due to the inability to measure $E_{\text {ox } 2}$ because of potential limitations of the medium.

from spectroelectrochemical and electrochemical studies of IVCT behavior, are each considered to provide a measure of valence localization/delocalization in dinuclear ligand-bridged complexes. Although they cannot be directly related, ${ }^{42}$ a qualitative comparison can be made between them, and if both methods were valid the trends for the same complexes in different electrolytes should be the same; however, it is clear they are not.

There are three main differences between the trends. First, from spectroelectrochemical studies of $\left[\left\{\mathrm{Ru}(\mathrm{bpy})_{2}\right\}_{2}(\mu \text {-dpo })\right]^{5+}$, across the series of anions, there is no discernible difference in the degree of delocalization between the two diastereoisomers (Figure 4). By contrast, electrochemically, there may be some indication that there is greater delocalization associated with the meso diastereoisomer in $0.1 \mathrm{M} \mathrm{PF}_{6}{ }^{-}$and $0.02 \mathrm{M} \mathrm{BF}_{4}{ }^{-}$ (Figure 4). Second, electrochemical studies of the same complex show that the relative effect of each electrolyte anion on the inter-metal communication is in the order $\mathrm{BF}_{4}^{-}>\mathrm{ClO}_{4}^{-}>$ $\mathrm{PF}_{6}{ }^{-}$for the rac diastereoisomer and $\mathrm{ClO}_{4}{ }^{-}>\mathrm{BF}_{4}{ }^{-}>\mathrm{PF}_{6}{ }^{-}$ 
for the meso diastereoisomer of the complex. The spectroelectrochemical results are not distinguishable for the diastereoisomeric pairs. Third, from electrochemical studies in solutions containing $0.02 \mathrm{M}\left[\left(n-\mathrm{C}_{4} \mathrm{H}_{9}\right)_{4} \mathrm{~N}\right] \mathrm{PF}_{6}$ and $\left[\left(n-\mathrm{C}_{4} \mathrm{H}_{9}\right)_{4} \mathrm{~N}\right]\left\{\mathrm{B}\left(\mathrm{C}_{6} \mathrm{~F}_{5}\right)_{4}\right\}$, both diastereoisomers show much larger $\Delta E_{\mathrm{ox}}$ values than with the other three electrolytes. In those inorganic electrolytes, the $\Delta E_{\mathrm{ox}}$ values for the rac isomer have similar magnitudes and there is variability for $\Delta E_{\mathrm{ox}}$ in the meso isomer (Figure 4). Nevertheless, there is a clear distinction between the $0.02 \mathrm{M}$ $\left[\left(n-\mathrm{C}_{4} \mathrm{H}_{9}\right)_{4} \mathrm{~N}\right] \mathrm{PF}_{6}$ and $\left[\left(n-\mathrm{C}_{4} \mathrm{H}_{9}\right)_{4} \mathrm{~N}\right]\left\{\mathrm{B}\left(\mathrm{C}_{6} \mathrm{~F}_{5}\right)_{4}\right\}$ solutions and the $0.1 \mathrm{M}\left[\left(n-\mathrm{C}_{4} \mathrm{H}_{9}\right)_{4} \mathrm{~N}\right] \mathrm{PF}_{6}, 0.02 \mathrm{M}\left[\left(n-\mathrm{C}_{4} \mathrm{H}_{9}\right)_{4} \mathrm{~N}\right] \mathrm{BF}_{4}$, and $0.02 \mathrm{M}$ $\left[\left(n-\mathrm{C}_{4} \mathrm{H}_{9}\right)_{4} \mathrm{~N}\right] \mathrm{ClO}_{4}$ solutions. Spectroelectrochemically, the inorganic anions have no discernible effect on $\Gamma$ compared with the weakly associating "baseline" of $\left[\left(n-\mathrm{C}_{4} \mathrm{H}_{9}\right)_{4} \mathrm{~N}\right]\left\{\mathrm{B}\left(\mathrm{C}_{6} \mathrm{~F}_{5}\right)_{4}\right\}$, and there is no clear distinction between the electrolytes as there was for the electrochemical methods.

The reasons why the different techniques provide different interpretations of the extent of localization/delocalization in mixed-valence dinuclear complexes is an important issue, as the literature contains many examples where $K_{\mathrm{c}}$ values have been used to compare electronic communication in such species. ${ }^{43-46}$ Many of these comparisons are very questionable, not only because of variations of conditions under which the determinations were made but also because there is an underlying unreliability of the electrochemically based method.

The comproportionation constant $K_{\mathrm{c}}$ is a measure of stability of the mixed-valence species, which has been shown ${ }^{12,45,47}$ to arise from the $\pi$-characteristics of the metal centers and bridging ligand, which also mediate the electron transfer. Accordingly, the comproportionation constant is also considered a measure of inter-metal communication. However, rather than measuring the stability of the mixed-valence species alone, it is conceivable that the electrochemically determined $K_{\mathrm{c}}$ is actually measuring the stability of the cation/anion(s) entity or some combination of the two factors. If that were so, the $K_{\mathrm{c}}$ expression in eq 2 would need to be modified to include the effects of the anion association for each oxidation process, which presume knowledge of the equilibrium data relating to the associations. A recent paper by Barriere and Geiger ${ }^{31}$ modifies the oxidation potentials for ion-pairing, which would support this argument. The stability (and equilibrium data) of the ion-pair would be highly dependent on the identity and concentration of the anion, and the stereochemical identity of the complex, which is verified by the variation in $K_{\mathrm{c}}$ seen in the present results. Accordingly, $K_{\mathrm{c}}$ derived electrochemically without modification may not be a totally reliable indication of delocalization or inter-metal electronic coupling as it is not a measure of the mixed-valence species alone. On the other hand, the parameter derived from the spectral measurement for delocalization, $\Gamma$, is determined from the dimensions of the IVCT band, which is predominantly dependent on charge transfer between molecular orbitals. The only effect on the orbitals by the inorganic anions in solution is to slightly distort them, and hence, their effect on delocalization is very small. Previous ion-pairing and thermochromism studies on related dinuclear systems ${ }^{7}$ have shown that as a result of the differential stereochemically directed anion effects, there is a small contribution to the redox asymmetry term $\left(\Delta E_{\mathrm{o}}\right)$ in eq 1 , and therefore on $\Gamma$ through its calculation using eqs 3 and 4. However, the effect is modest and the $\Gamma$ value determined spectrally in the present work-despite its qualitative natureis to be regarded as more reliable than the $K_{\mathrm{c}}$ parameter determined electrochemically from $\Delta E_{\mathrm{ox}}$.

\section{Conclusions}

Studies of the anion-dependence of the IVCT characteristics of the mixed-valence dinuclear ruthenium and osmium complexes of the structurally related bridging ligands dpo and dpi ${ }^{-}$ have given a significant insight into the role of the anion in the process.

Spectroelectrochemical studies of the diastereoisomeric forms of $\left[\left\{\mathrm{Ru}(\mathrm{bpy})_{2}\right\}_{2}\left(\mu-\mathrm{dpi}^{-}\right)\right]^{\mathrm{n}+}$ showed that the degree of valence delocalization is dependent on the stereochemical identity of the species and further that increasing the relative concentration of the strongly associating anion toluene-4-sulfonate in acetonitrile/[N( $\left.\left(n-\mathrm{C}_{4} \mathrm{H}_{9}\right)_{4}\right]\left\{\mathrm{B}\left(\mathrm{C}_{6} \mathrm{H}_{5}\right)_{4}\right\}$ solution differentially decreased the level of delocalization for the two diastereoisomers.

In a comparative investigation of electrochemical and spectroelectrochemical techniques of the anion-induced localization in $\left[\left\{\mathrm{Ru}(\mathrm{bpy})_{2}\right\}_{2}(\mu \text {-dpo })\right]^{5+}$, differences were observed between the two methods in the order and extent of effects induced by a number of inorganic anions $\left(\mathrm{PF}_{6}{ }^{-}, \mathrm{BF}_{4}{ }^{-}, \mathrm{ClO}_{4}{ }^{-}\right)$. The effect produced by the anion association was less important than the stereochemical identity of the complex. It was determined that the measure of delocalization derived from electrochemical methods was less reliable than that derived from spectral methods.

Acknowledgment. This work was supported by the Australian Research Council. We are grateful to Dr. Richard Webster (Australian National University, Canberra, Australia) for performing the electrochemical experiments with the carborane anion $\left(\mathrm{CB}_{11} \mathrm{H}_{6} \mathrm{Br}_{6}\right)^{-}$and to Professor Peter Steel (University of Canterbury, Christchurch, New Zealand) for providing the bridging ligands dpo and dpiH.

Supporting Information Available: ${ }^{1} \mathrm{H}$ NMR spectra of diastereoisomers of $\left[\left\{\mathrm{Os}(\mathrm{bpy})_{2}\right\}_{2}\left(\mu-\mathrm{dpi}^{-}\right)\right]\left(\mathrm{PF}_{6}\right)_{3}$ in $\mathrm{CD}_{3} \mathrm{CN}$ and NIR spectra for meso- $\left[\left\{\mathrm{Ru}(\mathrm{bpy})_{2}\right\}_{2}\left(\mu-\mathrm{dpi}^{-}\right)\right]^{4+}$ in acetonitrile solution containing varying ratios of toluene-4-sulfonate/ $\{\mathrm{B}-$ $\left.\left(\mathrm{C}_{6} \mathrm{~F}_{5}\right)_{4}\right\}^{-}$. This material is available free of charge via the Internet at http://pubs.acs.org.

\section{References and Notes}

(1) Creutz, C.; Taube, H. J. Am. Chem. Soc. 1973, 95, 1086-1094.

(2) Hush, N. S. Prog. Inorg. Chem. 1967, 8, 391-444.

(3) Hush, N. S. Electrochim. Acta 1968, 13, 1005-1023.

(4) Creutz, C. Inorg. Chem. 1978, 17, 3723-3725.

(5) Brunschwig, B. S.; Creutz, C.; Macartney, D. H.; Sham, T.-K.; Sutin, N. Faraday Discuss. 1982, 74, 113-127.

(6) Creutz, C. Prog. Inorg. Chem. 1983, 30, 1-73.

(7) D'Alessandro, D. M.; Junk, P. C.; Keene, F. R. Supramol. Chem. 2005, 17, 529-546.

(8) D'Alessandro, D. M.; Keene, F. R. Chem. Phys. 2006, 324, 8-25. (9) D'Alessandro, D. M.; Topley, A. C.; Davies, M. S.; Keene, F. R. Chem. Eur. J. 2006, 12, 4873-4884.

(10) Richardson, C.; Steel, P. J.; D’Alessandro, D. M.; Junk, P. C.; Keene, F. R. J. Chem. Soc., Dalton Trans. 2002, 2775-2785.

(11) Slater, J. W.; D'Alessandro, D. M.; Keene, F. R.; Steel, P. J. Dalton. Trans. 2005, 1954-1962.

(12) Kaim, W.; Kasack, V. Inorg. Chem. 1990, 29, 4696-4699.

(13) Heilmann, M.; Frantz, S.; Kaim, W.; Fiedler, J.; Duboc, C. Inorg. Chim. Acta 2006, 359, 821-829.

(14) Connelly, N. G.; Geiger, W. E. Chem. Rev. 1996, 96, 877-910

(15) Duff, C. M.; Heath, G. A. Inorg. Chem. 1991, 30, 2528-2535.

(16) D'Alessandro, D. M.; Keene, F. R. Chem. Eur. J. 2005, 11, 36793688.

(17) Reimers, J. R.; Hush, N. S. Inorg. Chem. 1990, 29, 3686-3697.

(18) D’Alessandro, D. M.; Keene, F. R. Chem. Soc. Rev. 2006, 35, 424440.

(19) Yeomans, B. D.; Kelso, L. S.; Tregloan, P. A.; Keene, F. R. Eur. J. Inorg. Chem. 2001, 239-246.

(20) Kelso, L. S. Ph.D. Thesis, James Cook University, Townsville, Queensland, Australia, 2000. 
(21) LeSuer, R.; Geiger, W. E. Angew. Chem., Int. Ed. 2000, 39, 248 250

(22) Buckingham, D. A.; Dwyer, F. P.; Goodwin, H. A.; Sargeson, A. M. Aust. J. Chem. 1964, 17, 325-336.

(23) D'Alessandro, D. M.; Davies, M. S.; Keene, F. R. Inorg. Chem. 2005, 45, 1656-1666.

(24) Juhasz, M.; Hoffmann, S.; Stoyanov, E.; Kim, K.-C.; Reed, C. A. Angew. Chem., Int. Ed. 2004, 43, 5352-5355.

(25) Fletcher, N. C.; Junk, P. C.; Reitsma, D. A.; Keene, F. R. J. Chem. Soc., Dalton Trans. 1998, 133-138.

(26) Fletcher, N. C.; Keene, F. R. J. Chem. Soc., Dalton Trans. 1999 683-689

(27) Keene, F. R. Chem. Soc. Rev. 1998, 27, 185-193.

(28) D'Alessandro, D. M.; Keene, F. R. New J. Chem. 2005, 30, 228237.

(29) Kaim, W.; Ernst, S.; Kasack, V. J. Am. Chem. Soc. 1990, 112 173-178.

(30) D'Alessandro, D. M.; Keene, F. R. Dalton Trans. 2004, 39503954.

(31) Barriere, F.; Geiger, W. E. J. Am. Chem. Soc. 2006, 128, 39803989.

(32) Reed, C. A. Chem. Commun. 2005, 1669-1677.

(33) Xie, Z.; Jelinek, T.; Bau, R.; Reed, C. A. J. Am. Chem. Soc. 1994 $116,1907-1913$.
(34) The lower concentration for the $\left[\left(n-\mathrm{C}_{4} \mathrm{H}_{9}\right)_{4} \mathrm{~N}\right]\left\{\mathrm{B}\left(\mathrm{C}_{6} \mathrm{~F}_{5}\right)_{4}\right\}$ electrolyte is determined by its limited solubility in acetonitrile.

(35) Hupp, J. T. Inorg. Chem. 1990, 29, 5010-5012.

(36) Ruiz, J.; Astruc, D. C. R. Acad. Sci. (Paris) 1998, 21-27. 9 .

(38) Cave, R. J.; Newton, M. D. Chem. Phys. Lett. 1996, 249, 15-19.

(39) Brunschwig, B. S.; Creutz, C.; Sutin, N. Chem. Soc. Rev. 2002, $31,168-184$.

(40) Robin, M. B.; Day, P. Adv. Inorg. Chem. Radiochem. 1967, 10 , 247-403.

(41) Demadis, K. D.; Hartshorn, C. M.; Meyer, T. J. Chem. Rev. 2001, $101,2655-2685$.

(42) The relationship between $\Delta E_{\mathrm{ox}}$ with $\lambda$ and $v_{\max }$ has been briefly discussed by Brunschwig and Sutin: Brunschwig, B. S.; Sutin, N. Coord. Chem. Rev. 1999, 187, 233-254.

(43) Richardson, D. E.; Taube, H. Inorg. Chem. 1981, 20, 1278-1285.

(44) Giuffrida, G.; Campagna, S. Coord. Chem. Rev. 1994, 135, 517531.

(45) Kalyanasundaram, K.; Nazeeruddin, M. K. Inorg. Chim. Acta 1994, $226,213-230$

(46) Ward, M. D. Chem. Soc. Rev. 1995, 24, 121-134

(47) Ernst, S.; Kasack, V.; Kaim, W. Inorg. Chem. 1988, 27, $1146-$ 1148 